\title{
The Selective Electrochemical Detection of Dopamine Using a Sulfated $\beta$-Cyclodextrin Carbon Paste Electrode
}

\author{
Gama Theophile Gnahore $^{1} \cdot$ Trinidad Velasco-Torrijos $^{1} \cdot$ John $_{\text {Colleran }}{ }^{2}$
}

Published online: 15 July 2017

(C) Springer Science+Business Media, LLC 2017

\begin{abstract}
The present work describes a novel approach for the determination of dopamine (DA) using carbon paste electrodes modified with sulfated $\beta$-cyclodextrin (S- $\beta$-CDCPE). The electrodes show high affinity towards DA electrochemical oxidation. DA returned a concentration detection range $5 \times 10^{-7} \mathrm{M}$ to $5 \times 10^{-4} \mathrm{M}$ and a detection limit of $1.33 \times 10^{-7} \mathrm{M}$. DA, ascorbic acid (AA), and serotonin (5HT) in a solution mixture can be simultaneously oxidized at significantly different potentials in the presence of S- $\beta$ CDCPE, while the unmodified CPE returned an overlapping response. In particular, S- $\beta$-CD-modified carbon paste microelectrode exhibits clear peak potential separations of 0.161 , 0.101 , and $0.258 \mathrm{~V}$ (vs. $\mathrm{Ag} / \mathrm{AgCl}$ ) for $\mathrm{AA} / \mathrm{DA}, \mathrm{DA} / 5-\mathrm{HT}$, and AA/5-HT, respectively, in artificial cerebrospinal fluid (aCSF).
\end{abstract}

Keywords Dopamine $\cdot$ Ascorbic acid · Serotonin . Simultaneous detection · Sulfated $\beta$-cyclodextrin . Microelectrode

Electronic supplementary material The online version of this article (doi:10.1007/s12678-017-0402-x) contains supplementary material, which is available to authorized users.

Gama Theophile Gnahore

GamaTheophile.Gnahore@nuim.ie

1 Department of Chemistry, Maynooth University, Maynooth, Co., Kildare, Ireland

2 School of Chemical and Pharmaceutical Sciences, Dublin Institute of Technology, Kevin Street, Dublin 8, Ireland

\section{Introduction}

Dopamine (DA) plays a very important role in the functioning of the central nervous system, with fluctuations in levels of DA in the cerebrospinal fluid linked to a variety of neurological and psychiatric disorders such as Parkinson's disease, schizophrenia, and Alzheimer's disease [1-4]. There is a continued and pressing interest in the development of simple and sensitive methods for the in vitro and in vivo quantification of DA. Electrochemical methods have been considered in several publications for the measurement of DA concentration in biological samples $[5,6]$. The issue associated with electrochemical determination of DA at common solid electrodes is the presence of a myriad of other electron active species, such as serotonin (5-HT) and ascorbic acid (AA), which populate the cerebrospinal fluid. AA is the main electroactive interferent and usually coexists with DA in extracellular fluid in high concentrations, approximately $10^{3}$ times higher than that of DA [7-10]. Moreover, DA and AA are oxidized at similar potentials at unmodified electrodes, which results in an overlapped voltammetric response. The electrochemical discrimination of DA from AA at unmodified electrodes using conventional electrochemical methods is difficult. Several works in the literature describe the development of new methodologies that employ modified electrodes for the selective detection of DA in the presence of AA $[2,11]$. The advantages of modified electrodes rely on their analytical applications, such as excellent sensitivity and selectivity, reproducibility, good stability and biocompatibility [12].

There are a limited number of examples published using cyclodextrin and its derivatives for the electrochemical detection of DA. Recently, Palanisamy et al. [13] have used a screen-printed carbon electrode (SPCE) modified with $\beta$-cyclodextrinentrapped graphite $(\mathrm{GR} / \beta-\mathrm{CD})$ composite as an electrochemical sensor for the detection of DA. The sensor detects DA in the 
linear concentration range from $1 \times 10^{-5} \mathrm{M}$ to $5.85 \times 10^{-5} \mathrm{M}$ with a limit of detection of $1.1 \times 10^{-8} \mathrm{M}$. Chen et al. [14] reported the use of GNPs/CDSH-Fc/Nafion ${ }^{\circledR}$ modified electrode for the selective detection of DA in the presence of AA. The sensor was fabricated by forming the inclusion complex between mono-6-thio- $\beta$-cyclodextrin (CD-SH) and ferrocene (Fc)-functionalized gold nanoparticle (GNP) films on a platinum electrode. A linear calibration curve was obtained over the DA concentration range $2 \times 10^{-6} \mathrm{M}$ to $5 \times 10^{-5} \mathrm{M}$ with a detection limit of $9 \times 10^{-8} \mathrm{M}$. Alarcon-Angeles et al. [15] utilized a combination of $\beta$-CD and multiwall carbon nanotubes (MWCNTs) drop-cast on a glassy carbon electrode. The detection of DA using amperometry was reported over the range $1 \times 10^{-5} \mathrm{M}$ to $8 \times 10^{-5} \mathrm{M}$, with a limit of detection $6.7 \times 10^{-6} \mathrm{M}$.

Other cyclodextrin sensors, based on sulfated cyclodextrin (as a modifier), for the electrochemical detection of DA have also been reported. Polypyrrole-sulfated cyclodextrin-modified glassy carbon electrodes [16] enabled the selective oxidation of DA in the presence of AA. The limit of detection was measured as $3.2 \times 10^{-6} \mathrm{M}$ for DA. Poly(3,4-ethylene dioxythiophene)/sulfated $\beta$-cyclodextrin (PEDOT/S- $\beta$-CD)modified gold electrodes [17] have been employed for the simultaneous detection of AA and DA in spiked human urine samples, with a limit of detection $1.8 \times 10^{-7} \mathrm{M}$ reported for DA. In all cases mentioned above, the performance characteristics of the electrochemical oxidation of DA (compared to the unmodified electrode) require the combination of cyclodextrin or derivatives with one or more dopants/modifiers. Moreover, it is reported [16] that AA does not exchange electrons with a polypyrrole-sulfated cyclodextrin electrode surface owing to the electrostatic repulsion between AA and S- $\beta-C D$. Therefore, in a solution mixture of AA and DA, the oxidation signal of DA is solely detected.

The present research work is aimed at designing a simple and reliable method based on a cyclodextrin derivative as the sole modifier for the electrochemical detection of DA, in the presence of AA and 5-HT. In this body of work, carbon paste electrodes (CPEs) modified with S- $\beta-\mathrm{CD}$ were fabricated and applied successfully for the simultaneous electrochemical detection of DA, AA, and 5-HT in phosphate buffer (PB) and aCSF. The three analytes were shown to be electrostatically attracted to the modified electrode surface through an enhancement of their respective anodic peak currents. The proposed sensor was miniaturized and could be exploited for the in vivo DA measurement.

\section{Experimental}

\section{Chemicals}

DA hydrochloride, ascorbic acid (AA), serotonin (5-HT) hydrochloride, neutral $\beta$-cyclodextrin, sulfated $\beta$-cyclodextrin sodium salt $(\mathrm{S}-\beta-\mathrm{CD})$, and graphite powder $(<20 \mu \mathrm{m})$ were purchased from Sigma-Aldrich and used as received. All other chemicals were of analytical reagent grade and were used without further purification. The main structural features of S- $\beta$-CD consist of a hydrophobic cavity and randomly distributed sulfated group on the CD rims. It is estimated by SigmaAldrich that the degree of sulfation per molecule of cyclodextrin ranges between 7 and 11 sulfate groups (see supplementary material Scheme S1). Ferrocene $\beta-C D$ was synthesized following the method described in the literature [18]. Successful synthesis of the ferrocene $\beta$-CD complex was achieved as demonstrated by IR characterization (see supplementary materials Fig. S1 and Table S1). The electrochemical electrolytes were prepared using Millipore ${ }^{\circledR}$ deionized water. In general, for electrochemical analysis, $0.1 \mathrm{M} \mathrm{PB}$ solution was used as the supporting electrolyte. $\mathrm{PB}$ was made of $\mathrm{K}_{2} \mathrm{HPO}_{4}$ and $\mathrm{KH}_{2} \mathrm{PO}_{4}$ to maintain a $\mathrm{pH}$ of 6.8. aCSF used to simulate the salt concentrations in the brain, consisted of $\mathrm{NaCl}\left(1.5 \times 10^{-2} \mathrm{M}\right), \mathrm{KCl}\left(4 \times 10^{-3} \mathrm{M}\right), \mathrm{CaCl}_{2}\left(1.6 \times 10^{-3} \mathrm{M}\right)$ and $\mathrm{MgCl}_{2}\left(2.1 \times 10^{-2} \mathrm{M}\right)$. All DA, AA, and 5-HT containing solutions were deaerated by purging with nitrogen for $15 \mathrm{~min}$ and freshly prepared prior to each experiment. The solutions were also protected from light for the duration of the experiments. All experiments were carried out at room temperature $\left(23 \pm 2{ }^{\circ} \mathrm{C}\right)$.

\section{Apparatus}

Cyclic voltammetry (CV) studies were accomplished using a Solartron potentiostat (model SI 1285A). Differential pulse voltammetry (DPV) was performed using a Chi440 potentiostat (Model 400). The three electrode system consists mainly of unmodified CPE or S- $\beta$-CDCPE working electrode (internal diameter $=1.6 \mathrm{~mm}$ ), a saturated calomel reference electrode (SCE), and a platinum wire counter electrode for experiments performed using macroelectrodes. In the case of the microelectrodes, a silver-silver chloride, $\mathrm{Ag} / \mathrm{AgCl}$ (internal diameter $=220 \mu \mathrm{m})$ and silver (internal diameter $=200 \mu \mathrm{m}$ ) wires served as reference electrode and counter electrode, respectively; while unmodified CPE or S- $\beta$-CDCPE (internal diameter $=200 \mu \mathrm{m})$ was employed as working electrodes. Arrows are displayed on each voltammogram to show the initial direction of the electrochemical sweep.

\section{Fabrication of Composite Carbon Paste Electrodes}

\section{Macroelectrode}

The modified carbon paste electrode was prepared by thoroughly hand-mixing the desired amount of S- $\beta-\mathrm{CD}$ and silicon oil with $0.71 \mathrm{~g}$ graphite powder in an agate mortar for approximately $30 \mathrm{~min}$ to yield a homogeneous S- $\beta-\mathrm{CD}$ modified carbon paste. To facilitate the homogeneity of the paste, 
both dry powders (graphite and sulfated $\beta$-cyclodextrin) were pre-mixed within a vial before grinding. The resulting composite material was then packed into one end of a Teflon tube (1.6-mm inner diameter), and electrical contact was made by insertion of a 1-mm-diameter copper rod at the other end. The Teflon holder was packed in small portions, each layer being compressed before adding the next. The electrode was polished on a piece of filter paper resulting in a smooth surface. The freshly made S- $\beta$-CDCPE was left to stand for $2 \mathrm{~h}$ to allow final homogenization. Fabrication of others sensors, neutral $\beta$-cyclodextrin-modified CPE $(\beta$-CDCPE) and ferrocene $\beta$-cyclodextrin complex-modified CPE (Fc- $\beta$-CDCPE), followed the same procedure. The unmodified $\mathrm{CPE}$ was also fabricated using the same process without addition of a modifying agent.

\section{Microelectrode}

The microelectrodes were prepared by using $5 \mathrm{~cm}$ lengths of a Teflon-insulated silver wire $(200 \mu \mathrm{m}$ bare diameter, $270 \mu \mathrm{m}$ coated diameter (8T), Advent Research Material, Suffolk, UK). Wire with the size of $3 \mathrm{~mm}$ was exposed by removing the Teflon from one end of the wire and the Teflon was carefully pushed up the wire to create a 2-mm cavity. The cavity was then packed with carbon composites. The $3 \mathrm{~mm}$ of exposed wire was soldered into a gold clip for electrical conductivity and rigidity [19]. It is worth noting that the S- $\beta-C D$ carbon composite was prepared as explained previously, by thoroughly hand-mixing the desired amount of S- $\beta-C D$ with $0.71 \mathrm{~g}$ graphite powder and $200 \mu \mathrm{L}$ silicon oil in an agate mortar for $30 \mathrm{~min}$. To differentiate between the standard electrode (macroscale) and the microelectrode, the latter is denoted as $m S$ - $\beta$-CDCPE.

\section{Results and Discussion}

\section{DA Electrochemical Redox Process at S- $\beta$-CDCPE}

The S- $\beta$-CDCPE (prepared with an optimal amount of S- $\beta$ $\mathrm{CD}, 0.545 \mathrm{~g}$ ) exhibited excellent electroanalytical response towards the oxidation of DA as demonstrated by comparison to the unmodified CPE. A typical cyclic voltammogram of $5 \times 10^{-5} \mathrm{M}$ DA in a $0.1 \mathrm{M} \mathrm{PB}(\mathrm{pH}$ 6.8) at an unmodified $\mathrm{CPE}$ is shown in Fig. 1 (trace a). The voltammogram is characterized by the appearance of distinct anodic peak $(0.225 \mathrm{~V}$ vs. SCE) and cathodic peak ( $0.092 \mathrm{~V}$ vs. SCE), with a peak potential separation, $\Delta E_{\mathrm{p}}$, of $0.133 \mathrm{~V}$ and the redox peak currents $\left(I_{\mathrm{pa}} / I_{\mathrm{pc}}\right)$ ratio of 1.20 . The oxidation and reduction peak currents were found to be $2.25 \times 10^{-7} \mathrm{~A}$ and $1.88 \times 10^{-7} \mathrm{~A}$, respectively. Under identical conditions, the $\mathrm{S}$ - $\beta$-CDCPE produces a remarkable increase in the magnitude of DA peak currents, with a near 10-fold peak current enhancement, at S- $\beta$-CDCPE, compared to the unmodified CPE (Fig. 1, trace b). The oxidation and reduction peak currents were $2.44 \times 10^{-6} \mathrm{~A}$ and $2.45 \times 10^{-6} \mathrm{~A}$, respectively, yielding an $I_{\mathrm{pa}} / I_{\mathrm{pc}}$ ratio of unity. These results strongly indicate that the presence of S- $\beta$-CD improved the sensitivity of the carbon paste towards the electrochemical detection of DA. In addition, the oxidation and reduction peak potentials occur at 0.172 and $0.153 \mathrm{~V}$ (vs. SCE), respectively, giving a peak potential separation $\left(\Delta E_{\mathrm{p}}\right)$ of $0.019 \mathrm{~V}$, which is smaller than the predicted $\Delta E_{\mathrm{p}}$ for a diffusion-controlled reversible reaction $\left(\Delta E_{\mathrm{p}}=0.03 \mathrm{~V}\right.$ for DA electro-oxidation).

\section{Mechanism of Electrochemical Oxidation of DA at $\mathrm{S}-\beta-\mathrm{CDCPE}$}

To elucidate the mechanism of DA oxidation at S- $\beta$-CDCPE, a relatively wide electrochemical window (from -0.4 to $+0.4 \mathrm{~V}$ ) was employed. Four different concentrations of DA $\left(5 \times 10^{-5} \mathrm{M}, 1 \times 10^{-4} \mathrm{M}, 5 \times 10^{-4} \mathrm{M}\right.$, and $\left.1 \times 10^{-3} \mathrm{M}\right)$ were investigated in a $0.1 \mathrm{M} \mathrm{PB}$ at $\mathrm{pH}$ 6.8. As displayed in Fig. 2, two pairs of redox peaks are observed, which increase in current with increasing DA concentration.

The first step of DA oxidation involves a two-electron transfer to generate dopaminoquinone (DOQ). DOQ undergoes a cyclization process, through 1,4-Michael addition [20-22], leading to the formation of leucodopaminechrome (LC). Since the $\mathrm{p} K_{\mathrm{a}}$ of DA is $8.9[23,24]$, below the $\mathrm{pH}$ value of 8.9, the protonated form of DA is predominant in solution, suggesting a poor nucleophilicity of the DA amino group for the 1,4-Michael addition reaction. However, in a solution of $\mathrm{pH} 6.8$, the amount of unprotonated DOQ is sufficient for the cyclization reaction to occur. Therefore, the electroactive product, LC, is reversibly oxidized to dopaminechrome (DC) which manifests as a small redox couple. A similar result at a glassy carbon-modified electrode was obtained experimentally [25]. From Fig. 2, the pair of redox peaks observed at the positive potentials (DA/DOQ) corresponds to the first electrochemical step, whereas the pair of redox peaks observed at the negative potentials (LC/DC) describes the second electrochemical step. The cyclization of DOQ, sandwiched between the two electrochemical steps, is a homogeneous reaction $[26,27]$. Thus, the oxidation of DA at S- $\beta$-CDCPE can be classified an ECE mechanism, where E and $\mathrm{C}$ denote the electrochemical and chemical steps, respectively. Moreover, the oxidation of LC to DC, observed only after the first cycle (see supplementary material Fig. S2), generates further support that the electrochemical redox processes of DA at S- $\beta$-CDCPE follows an ECE mechanism.

Although, a detailed mechanism for the electrochemical oxidation of DA was described above, DA detection is often simplified by using a potential window that limits the redox region to that of the DA/DOQ redox couple-as was employed in this body of work. 
Fig. 1 Typical cyclic voltammograms of DA $\left(5 \times 10^{-5} \mathrm{M}\right)$ in $0.1 \mathrm{M} \mathrm{PB}$ (pH 6.8) at unmodified CPE (trace $a$ ) and S- $\beta$-CDCPE (trace b). Inset: enlarged cyclic voltammogram of the unmodified CPE. Scan rate $50 \mathrm{mV} / \mathrm{s}$

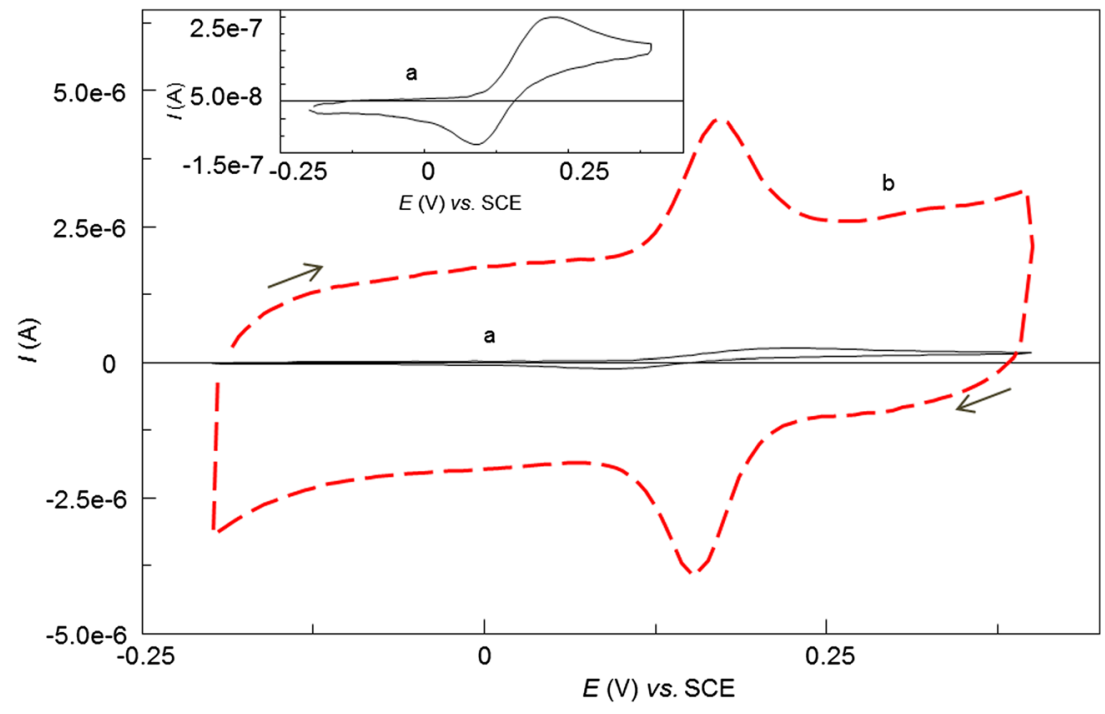

\section{The Effect of the Concentration of S- $\beta-C D$ on the Electrochemistry of DA}

The effect of the amount of S- $\beta-C D$ in the modified CPE on DA oxidation peak current was investigated using cyclic voltammetry. In this study, a number of S- $\beta$-CDCPEs were prepared with different ratios of S- $\beta-\mathrm{CD} /$ graphite/silicone oil. Typically, the S- $\beta$-CD was varied from 0.145 to $0.895 \mathrm{~g}$ in increments of $0.050 \mathrm{~g}$. The cyclic voltammetry experiments were carried out in triplicate, and the average value of the DA oxidation peak current was recorded. The oxidation peak current of DA increased remarkably by increasing the amount of S- $\beta$-CD from 0.145 to $0.495 \mathrm{~g}$ as shown in Fig. 3. An apparent steady-state current response for DA oxidation was obtained at electrodes with S- $\beta-C D$ in quantities greater than 0.495 up to $0.695 \mathrm{~g}$. However, the oxidation peak currents of DA decreased greatly when the amount of S- $\beta-C D$ exceeded
$0.695 \mathrm{~g}$. These experimental results suggest that an amount of S- $\beta$-CD, lower than $0.495 \mathrm{~g}$, is not sufficient to favor optimum peak currents for DA oxidation, and amounts higher than $0.695 \mathrm{~g}$ can inhibit the electrical conductivity of carbon paste. The range from 0.495 to $0.695 \mathrm{~g}$ was considered the optimal amount of S- $\beta-C D$ for the electrochemical detection of DA. Consequently, $0.545 \mathrm{~g}$ was chosen as the mass of S- $\beta$ $\mathrm{CD}$ required to generate composite $\mathrm{CPE}$ with optimal sensitivity toward DA oxidation.

\section{Evidence of the Interaction of S- $\beta-C D$ with DA}

\section{Effect of Scan Rate on the Peak Current of DA at S- $\beta-C D C P E$}

The effect of scan rate on the peak current of a $5 \times 10^{-5} \mathrm{M} \mathrm{DA}$ solution at S- $\beta$-CDCPE was investigated using cyclic voltammetry. It was found that the anodic peak current of DA
Fig. 2 Cyclic voltammograms of various concentrations of DA $\left(5 \times 10^{-5} \mathrm{M}, 1 \times 10^{-4} \mathrm{M}\right.$, $5 \times 10^{-4} \mathrm{M}$, and $\left.1 \times 10^{-3} \mathrm{M}\right)$ in $0.1 \mathrm{M}$ PB (pH 6.8) at S- $\beta$ CDCPE using an electrochemical window over the range of -0.4 to $+0.4 \mathrm{~V}$. Scan rate $50 \mathrm{mV} / \mathrm{s}$

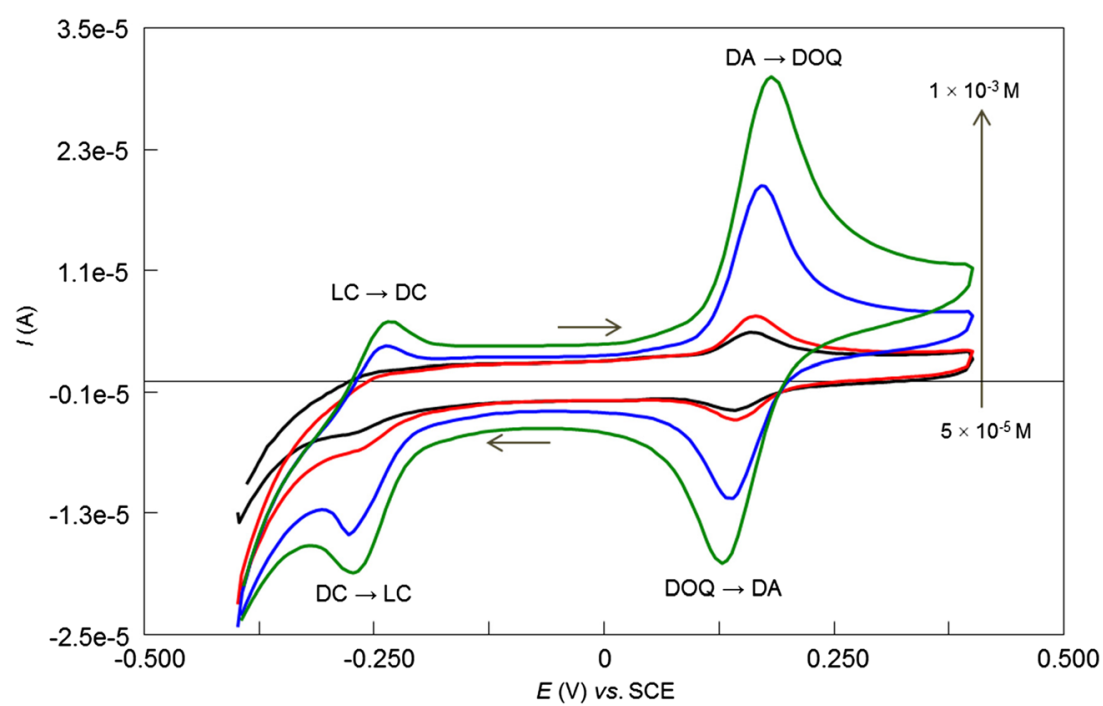


Fig. 3 Effect of the concentration of $S-\beta-C D$ on the DA oxidation peak current. Cyclic voltammograms recorded using $5 \times 10^{-5} \mathrm{M}$ $\mathrm{DA}$ in $0.1 \mathrm{M} \mathrm{PB}$ at the scan rate $50 \mathrm{mV} / \mathrm{s}$

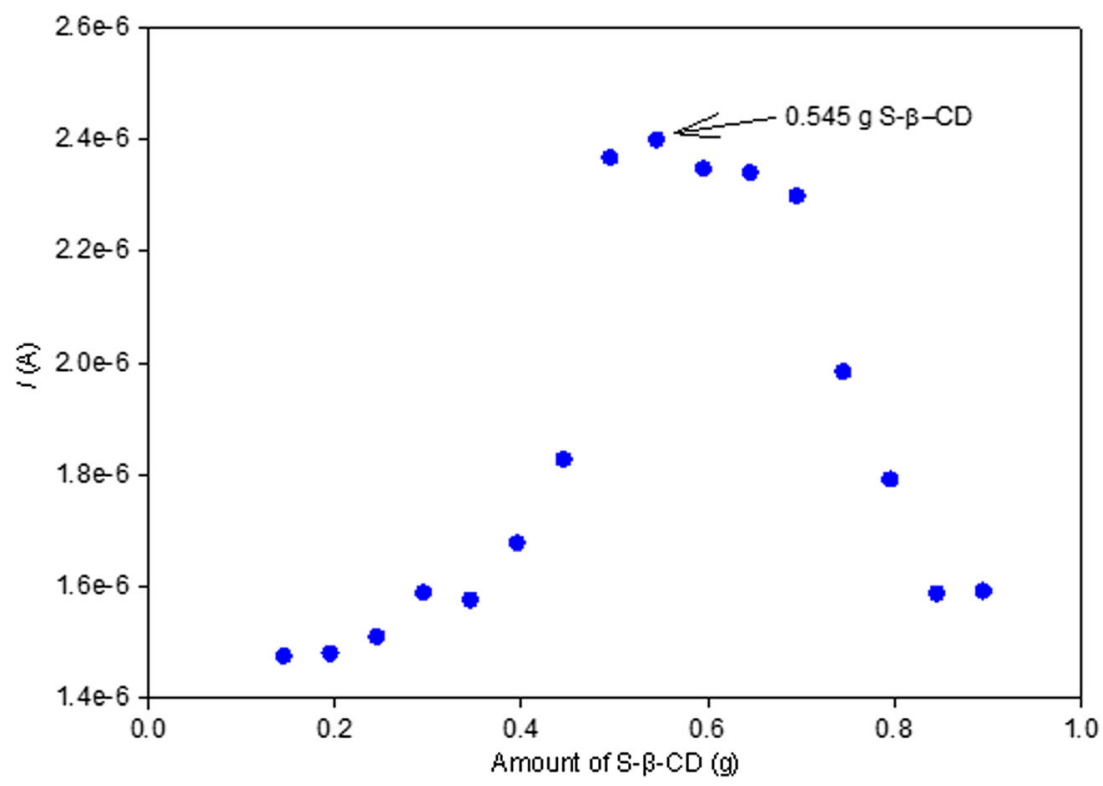

increased linearly with the scan rate over the range of 10 to $80 \mathrm{mV}$ vs. SCE (Fig. 4a), indicating the oxidation of DA is under adsorption-control at the modified electrode within the studied electrochemical range. The regression equation is $I_{\mathrm{pa}}$ (A) $=3.102 \times 10^{-8} \nu+5.269 \times 10^{-7}$, with a correlation coefficient of 0.9943 (Fig. 4b).

Furthermore, to demonstrate the adsorption ability of S- $\beta$ CDCPE, a pre-concentration experiment was performed by immersing unmodified CPE and S- $\beta$-CDCPE separately in $5 \times 10^{-5} \mathrm{M}$ DA solutions for $5 \mathrm{~min}$. After rinsing both electrodes with distilled water, cyclic voltammograms were recorded in a fresh DA-free PB solution. DA oxidation signals were not observed at unmodified $\mathrm{CPE}$, while DA redox peaks were clearly obtained at S- $\beta$-CDCPE (see supplementary material Fig. S3). This result demonstrates that DA is significantly adsorbed onto the surface of the modified electrode due to the presence of $S-\beta-C D$. It should be noted that with successive cycling of the $S-\beta-C D C P E$ in buffer, a reduction and subsequent disappearance of the DA redox peaks was observed.

\section{Effect of Scan Rate on the Peak Current of DA at Neutral $\beta-C D C P E$}

In order to verify the ability of the cyclodextrin cavity to influence the electron transfer processes at the electrode surface, and to clarify the extent of the electrostatic interactions between the sulfate groups and protonated DA, S- $\beta-C D$ was replaced with neutral $\beta$-cyclodextrin $(\beta-C D)$. The influence of scan rate on the voltammetric response to DA oxidation
Fig. 4 a Cyclic voltammograms of DA $\left(5 \times 10^{-5} \mathrm{M}\right)$ recorded at $\mathrm{S}$ $\beta$-CDCPE at different scan rates $(10,20,40,60$, and $80 \mathrm{mV} / \mathrm{s})$; b the corresponding plot of anodic peak current as a function of scan rate. Supporting electrolyte $0.1 \mathrm{M}$ PB (pH 6.8)
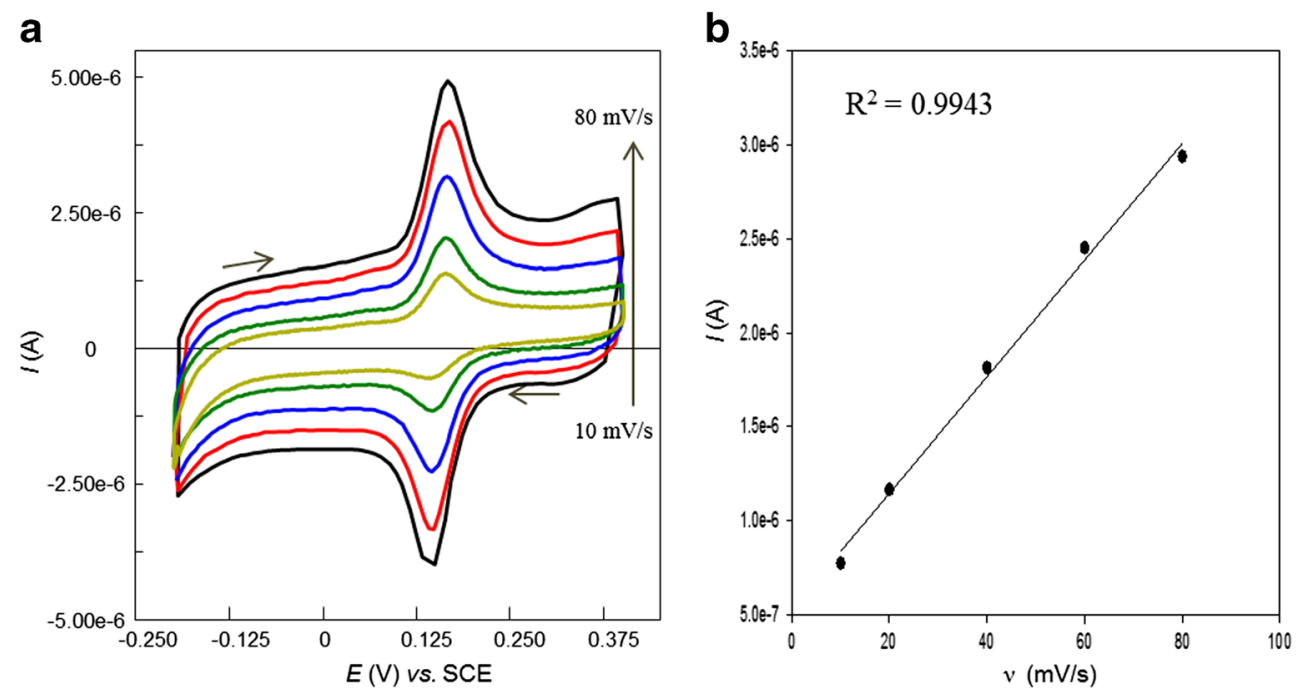
was investigated to diagnose the mechanism of the electrochemical oxidation of DA at neutral $\beta$-CDCPE (see supplementary material Fig. S4). It is clear that the oxidation peak current increases linearly with applied scan rate, indicative of an adsorption-controlled process. The regression equation returned was $I_{\mathrm{pa}}(\mathrm{A})=5.404 \times 10^{-9} \nu+1.055 \times 10^{-7}$, with a correlation coefficient of 0.9898 . This result suggests that the electron transfer process for DA oxidation is similar to that observed at S- $\beta$-CDCPE. On the other hand, the electrochemical process at the unmodified CPE was observed to be mainly diffusion-controlled (see supplementary material Fig. S5). The plot of the logarithm of oxidation peak currents against the logarithm of scan rate at unmodified CPE shows a linear relationship with a corresponding equation $\log I=0.5062$ $\log v-7.4085\left(R^{2}=0.9831\right)$. The slope is comprised in the range from 0.5 to 1 and indicates that the electron transfer at the unmodified CPE is predominantly under a diffusion process according to Laviron [28].

Although the oxidation peak currents of DA obtained at neutral $\beta$-CDCPE (at the scan rates studied) are higher than those recorded at the unmodified $\mathrm{CPE}$ under identical conditions, neutral $\beta$-CDCPE exhibits much smaller DA oxidation peak currents when compared to S- $\beta$-CDCPE. These results also indicate that the negative charges on cyclodextrin play an important role in initial long-range DA interaction, while the mode of interaction between neutral $\beta$-CDCPE and DA is based solely on host-guest inclusion, the main driving force for complex formation being hydrophobic interaction. It must be pointed out that the primary and secondary rims of $\beta-C D$ are exclusively populated with $-\mathrm{OH}$ group. Hemmateenejad et al. [29] and Goa et al. [30] studied the inclusion complex formed between DA and neutral $\beta-C D$ using a chronoamperometric and cyclic voltammetry techniques, respectively. The authors found that the inclusion complex has a 1:1 stoichiometry. These early works support the evidence of the formation of an inclusion complex between neutral CD and DA obtained in this body of work.

\section{Effect of Scan Rate on the Peak Current of DA at $F C-\beta-C D C P E$}

To further support the premise that the enhanced peak currents for DA oxidation obtain at the composite electrode are attributed to the host-guest inclusion properties of the cyclodextrin cavity, a ferrocene $\beta-\mathrm{CD}$ inclusion complex (Fc- $\beta-\mathrm{CD})$ was synthesized and used as the electrode modifier. To generate this inclusion complex, ferrocene was incorporated into the $\beta$-CD cavity. The rationale behind the blockage of the $\beta-\mathrm{CD}$ cavity is to inhibit the host-guest interaction of neutral $\beta-C D$ with DA. The increase in potential scan rate at $\mathrm{Fc}-\beta$-CDCPE led to a corresponding increase in peak current, and a shift to more anodic values, for the oxidation of DA (see supplementary materials Fig. S6). Furthermore, the peak current varies linearly with the square root of the scan rate, with a linear equation presented as follows: $I_{\mathrm{pa}}(\mathrm{A})=2.231 \times 10^{-6} \nu^{1 / 2}+$ $5.153 \times 10^{-10}$. Therefore, compared to neutral $\beta$-CDCPE, which exhibits an adsorption-controlled process for the oxidation of DA, Fc- $\beta$-CDCPE follows a diffusion-controlled process. This change in electrochemical system demonstrates that ferrocene blocks the access of DA to be included into the cyclodextrin cavity. Thus, the oxidation of DA is only possible when DA molecules, approaching the surface of the modified electrode, are oxidized through the catalytic effect of the ferrocene moiety. The resulting oxidative peak currents rely on the reaction between ferrocenium ion and DA [31]. An enhanced current response was observed at $\mathrm{Fc}-\beta$-CDCPE compared to the unmodified CPE (see supplementary materials Fig. S7). Moreover, the peak separation for the DA redox process at Fc- $\beta$-CDCPE $\left(\Delta E_{\mathrm{p}}=0.110 \mathrm{~V}\right)$ was smaller than that at the unmodified CPE $\left(\Delta E_{\mathrm{p}}=0.280 \mathrm{~V}\right)$. Therefore, the role of the modifier is not only to intensify the peak current but also to decrease the overpotential for DA oxidation. Consequently, reversibility of DA is enhanced using Fc- $\beta-C D$.

\section{Mode of DA Electrochemical Sensing at S- $\beta-C D C P E$}

The mode of sensing of S- $\beta$-CDCPE was considered from two perspectives. Firstly, the pre-concentration experiment referred to previously indicates that DA interacts with $S-\beta-C D$ at the electrode/solution interface. A strong electrostatic attraction of the electronegative sulfate groups with the positively charged DA molecule are more likely to occur at $\mathrm{pH} 6.8$. Secondly, the electrostatic interaction may help to facilitate the inclusion of protonated DA in the cavity of cyclodextrin, thus, enhancing the rate of electron transfer at the electrode surface. Previous studies based on nuclear magnetic resonance (NMR) have shown that DA forms a 1:1 inclusion complex in solution with S- $\beta-C D$ [32]. Therefore, the formation of an inclusion complex between $S-\beta-C D$ and $D A$, where the aromatic ring of DA is inserted into the S- $\beta$-CD cavity, may justify the remarkable increase in DA oxidation peak current observed at S- $\beta$ CDCPE. The effect of S- $\beta-C D$ on the peak intensity was also examined using the more sensitive technique differential pulse voltammetry (DPV) (see supplementary materials Fig. S8). Similar to the cyclic voltammetry, DPV shows a 10 -fold increase in DA oxidation peak currents at S- $\beta$-CDCPE and provides strong evidence that the presence of $S-\beta-C D$ greatly improves the sensitivity of the carbon paste towards the electrochemical detection of DA.

\section{pH Effect on DA Redox Process}

The effect of $\mathrm{pH}$ on the electrode response was studied over the range $\mathrm{pH} 4$ to 9 . Fig. 5a illustrates typical cyclic voltammograms of $5 \times 10^{-5} \mathrm{M}$ DA at different $\mathrm{pH}$ solutions. It was found that DA redox peak currents increase with an increase 
Fig. 5 a Cyclic voltammograms of DA $\left(5 \times 10^{-5} \mathrm{M}\right)$ in $0.1 \mathrm{M} \mathrm{PB}$ at different $\mathrm{pH}$ values (from 4 to $9)$, recorded at $\mathrm{S}-\beta-\mathrm{CDCPE}$ at a scan rate of $50 \mathrm{mV} / \mathrm{s}$; $\mathbf{b}$ the corresponding plot of anodic peak potential $\left(E_{\mathrm{pa}}\right)$ as a function of $\mathrm{pH}$

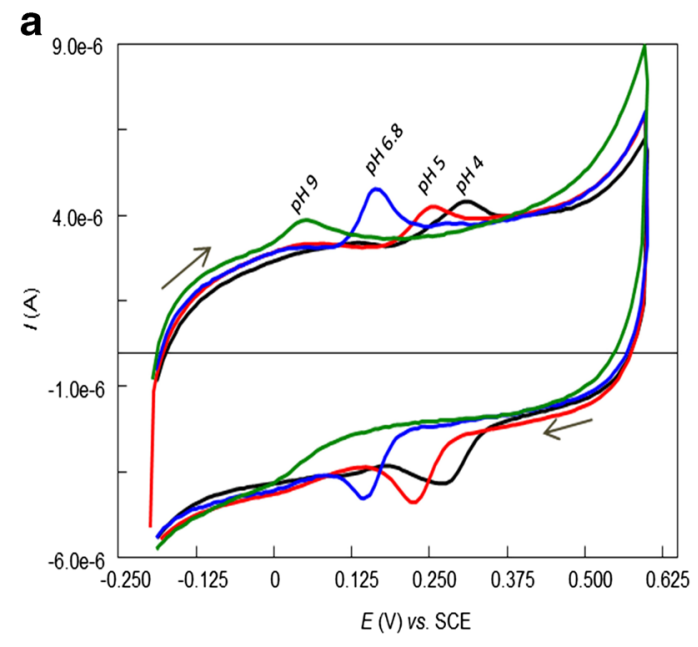

b

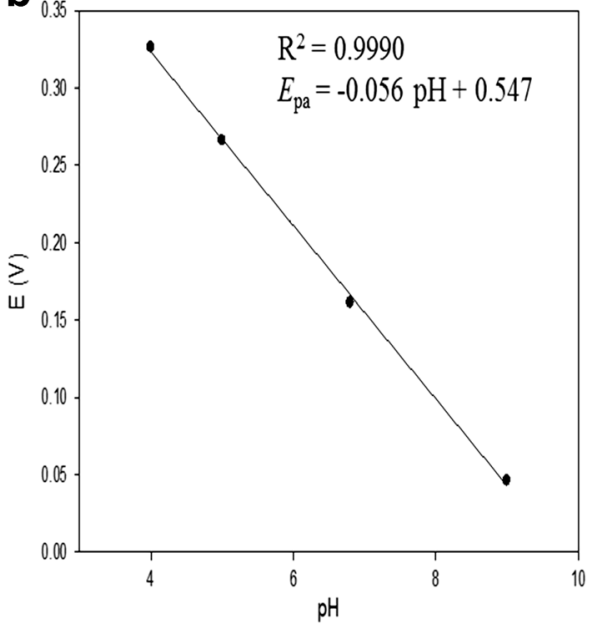

in $\mathrm{pH}$ up to 6.8. Thereafter, the redox peak currents decreased at $\mathrm{pH}$ values greater than 6.8 . The peak potential was found to shift cathodically with increasing $\mathrm{pH}$, indicating that the number of electrons and protons is the same throughout the electrochemical oxidation process of DA $[15,33]$. As shown in Fig. 5b, the DA anodic peak potential is linearly proportional to the solution $\mathrm{pH}$ with a slope of $-0.056 \mathrm{~V}$ per unit $\mathrm{pH}$, which is very close to the theoretical Nernstian slope $(-0.059 \mathrm{~V})$. This result supports the $2 e^{-} / 2 \mathrm{H}^{+}$redox reaction system [34], since two electrons are transferred.

\section{Simultaneous Detection of $D A$ and $A A$ at $S-\beta-C D C P E$}

The ability to separate the voltammetric signal of AA and DA is of great significance as their oxidation potentials are very similar at common unmodified electrodes, resulting in an overlapping voltammetric response. The investigation into the electrochemical behavior of AA and DA at unmodified CPE was performed using cyclic voltammetry in AA/DA solution mixtures $\left([\mathrm{AA}]=1 \times 10^{-3} \mathrm{M},[\mathrm{DA}]=5 \times 10^{-5} \mathrm{M}\right.$ in $\left.0.1 \mathrm{M} \mathrm{PB}\right)$ as illustrated in Fig. 6 (trace a). The oxidation of the two species results in an overlapping voltammetric response, demonstrating that DA cannot be accurately detected. In addition, the oxidized DA product, DOQ, can be homogeneously catalytically reduced to DA by AA $[2,35,36]$ resulting in in situ generation of DA at the electrode surface, available for oxidation. These observations clearly indicate that the presence of AA is detrimental to the determination of DA at unmodified CPEs. Under identical experimental conditions, typical cyclic voltammograms obtained at S- $\beta$-CDCPE in a solution mixture of AA and DA exhibits two distinct oxidation peaks for both analytes as illustrated in Fig. 6 (trace b). The (broad) oxidation peak for AA is visible at $c a .0 .014 \mathrm{~V}$, while the DA oxidation peak is observed at $0.161 \mathrm{~V}$ vs. SCE. So, compared to unmodified CPE, S- $\beta$-CDCPE resolved the voltammetric response of AA and DA into two distinct oxidation peaks. The separation between the oxidation peak potential of AA and DA $(0.147 \mathrm{~V}$ vs. SCE) is large enough for the simultaneous determination of DA and AA at S- $\beta$-CDCPE.

In order to understand the electron transfer processes of DA and AA oxidation in a solution mixture at the S- $\beta$ CDCPE, the effect of scan rate on the oxidation peak potential and peak currents was studied, with resultant typical cyclic voltammetric curves shown in Fig. 7a. When the scan rate is increased, the oxidation peak potential for AA shifts to more anodic values, while that of DA remains constant. The anodic shift of AA oxidation peak potentials with increasing scan rate may indicate a slow kinetics of the interfacial electron transfer of AA. However, the oxidation peak current of $\mathrm{AA}$ is proportional to the scan rate over the range of 10 to $80 \mathrm{mV} / \mathrm{s}$, as illustrated in Fig. 7b, with a linear regression equation of $I_{\mathrm{pa}}(\mathrm{A})=1.433 \times 10^{-8} v+2.247 \times 10^{-6}$. Furthermore, the variation of the logarithm of the peak current as a function of the logarithm of the scan rate yields the linear regression equation, $\log I=1.1645 \log v-1.6674$, with a slope value close to 1 (see supplementary material Fig. S9). Thus, the oxidation of AA in the solution mixture at S- $\beta$ CDCPE is under an adsorption-controlled process over the scan rate range studied. This experimental result was unexpected due to the charge carried by $\mathrm{AA}$ and $\mathrm{S}-\beta-\mathrm{CD}$ at $\mathrm{pH}$ 6.8. AA $\left(\mathrm{p} K_{a}=4.10\right)$ exists mostly in anionic form at $\mathrm{pH}$ 6.8. The modified electrode is also negatively charged at the studied $\mathrm{pH}$ due to the sulfate groups present on the rim(s) of cyclodextrin. Therefore, in theory, the sulfate groups are expected to inhibit the approach of AA anions to the electrode surface, which may result in an apparent diffusion process. However, the mechanism diagnosis of AA at S- $\beta$-CDCPE (adsorption-controlled process) strongly suggests that some amount of AA may reach the electrode surface, overcoming the repulsion. At the electrode/solution interface, AA is oxidized easily, probably facilitated through hydrogen bonding. It is also important to recall that $\mathrm{S}-\beta$-CDCPE is made of 
Fig. 6 Typical cyclic voltammograms obtained in a solution mixture of $5 \times 10^{-5} \mathrm{M}$ DA and $1 \times 10^{-3} \mathrm{M}$ AA recorded at unmodified CPE (trace $a$ ) and at S- $\beta$-CDCPE (trace $b$ ). Supporting electrolyte $0.1 \mathrm{M} \mathrm{PB}$ (pH 6.8). Scan rate $50 \mathrm{mV} / \mathrm{s}$

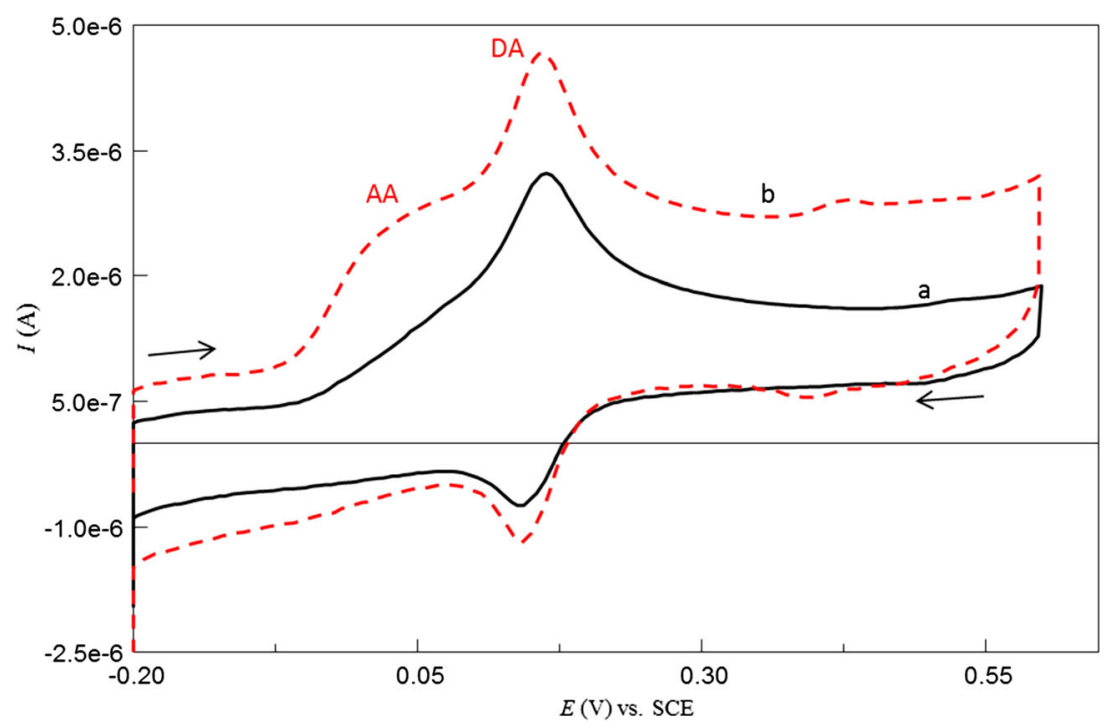

cyclodextrin containing from 7 to 11 sulfate groups per molecule. A repulsive force may occur between the negatively charged sulfates. Thus, hydrogen bonding between AA and several hydroxyl groups at the inner and/or outer rims of S- $\beta$ $\mathrm{CD}$ is facilitated. Another important observation from Fig. 7a is the AA peak shape. At fast scan rate, the oxidation of AA occurs as a plateau current. However, at slow scan rate, the response of AA oxidation exhibits a clear peak shape which indicates that AA molecules have sufficient time to interact with $S-\beta-C D$. Furthermore, the influence of the concentration of $\mathrm{S}-\beta-\mathrm{CD}$ on the redox process of AA shows that the oxidation peak current of AA increases as the amount of S- $\beta-C D$ (within the carbon paste) is increased (see supplementary material Fig. S10). Interestingly, the corresponding peak potentials shift cathodically with an increase of S- $\beta-C D$, which suggests that AA electron transfer is more facile in the presence of $S-\beta-C D$. On the other hand, the anodic peak current of DA in the solution mixture at the modified electrode also increased linearly with the scan rate, confirming that DA is adsorbed at the surface of S- $\beta$-CDCPE. Fig. $7 \mathrm{~b}$ presents the reasonable linearity of the plots, with a regression equation of $I_{\text {pa }}(\mathrm{A})=3.713 \times 10^{-8} v+8.288 \times 10^{-7}$ and correlation coefficient of 0.9935 . The results clearly demonstrate that S- $\beta$-CD has the ability to interact with both species in solution of coexisting DA and AA species and separate their respective voltammetric signals.

It was demonstrated previously that $S-\beta-C D C P E$ exhibits an enhanced activity towards the detection of DA, when compared to unmodified CPE. Therefore, the response of various concentrations of DA at the modified electrodes was studied. Firstly, different DA concentrations were investigated at the macroscale modified electrode (S- $\beta$-CDCPE). The concentration of DA was varied from $5 \times 10^{-6} \mathrm{M}$ to $1 \times 10^{-3} \mathrm{M}$, using cyclic voltammetry. It is clear that the oxidation peak current of DA increases with increasing DA concentration as shown in Fig. 8a. A similar trend was observed in Fig. 8b, which shows typical cyclic voltammograms, obtained at S- $\beta$ CDCPE in solution mixtures of $1 \times 10^{-3} \mathrm{MAA}$ and increasing
Fig. 7 a Cyclic voltammograms showing the effect of scan rate variation for a solution mixture of DA $\left(5 \times 10^{-5} \mathrm{M}\right)$ and AA $\left(1 \times 10^{-3} \mathrm{M}\right)$ in $0.1 \mathrm{M} \mathrm{PB}$ (pH 6.8) recorded at $\mathrm{S}-\beta-\mathrm{CDCPE}$ at different scan rates $(10,20,40$, 60 , and $80 \mathrm{mV} / \mathrm{s}$ ); b the corresponding plots of anodic peak current of AA and DA as a function of scan rate
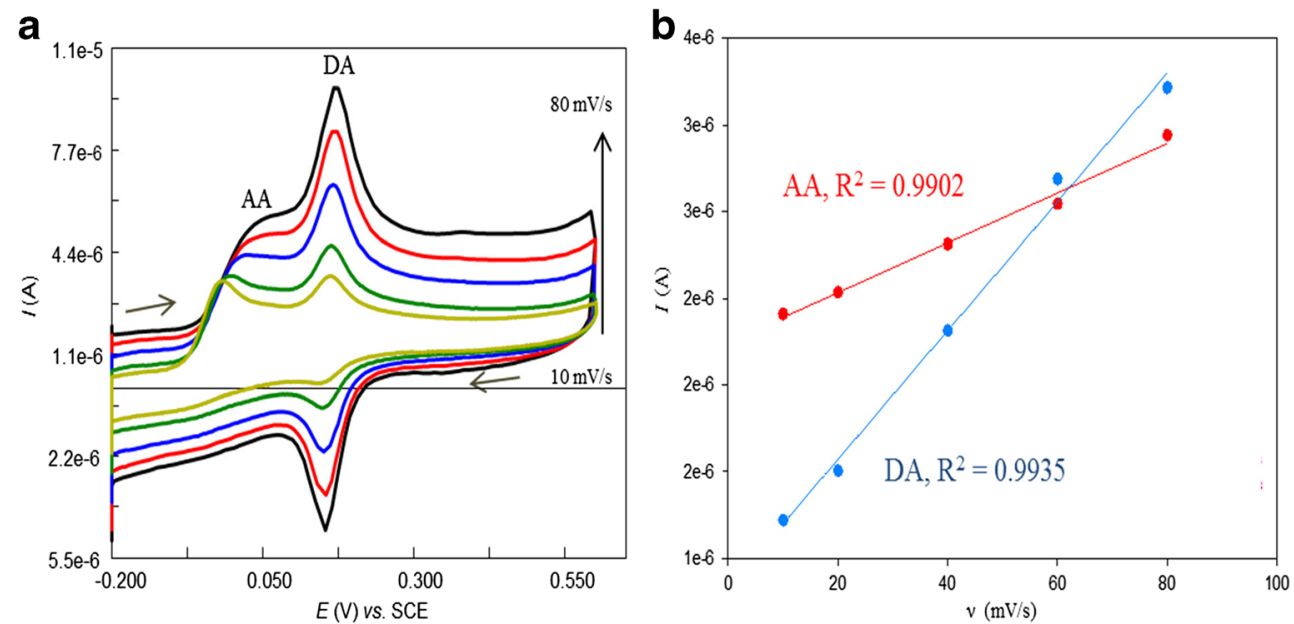
a

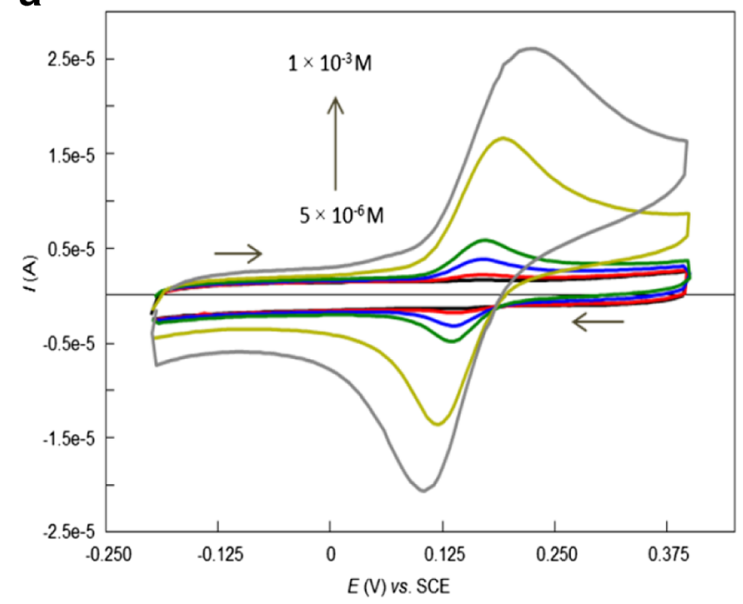

b

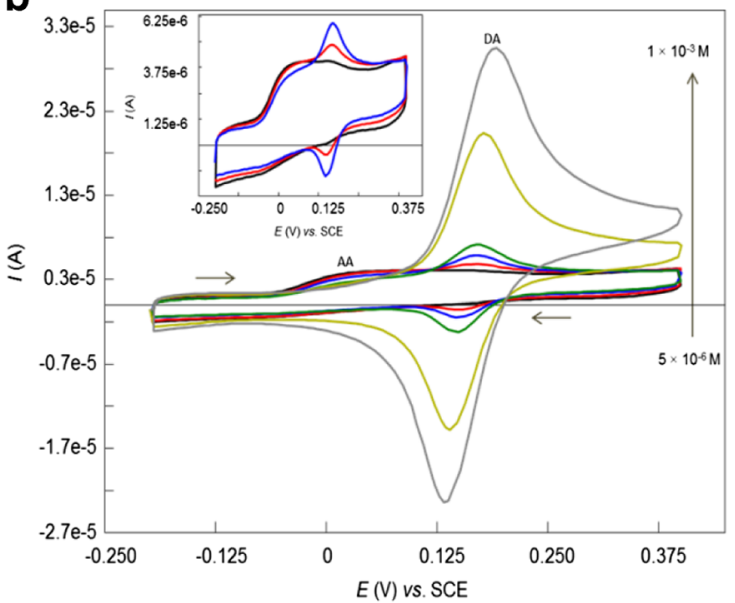

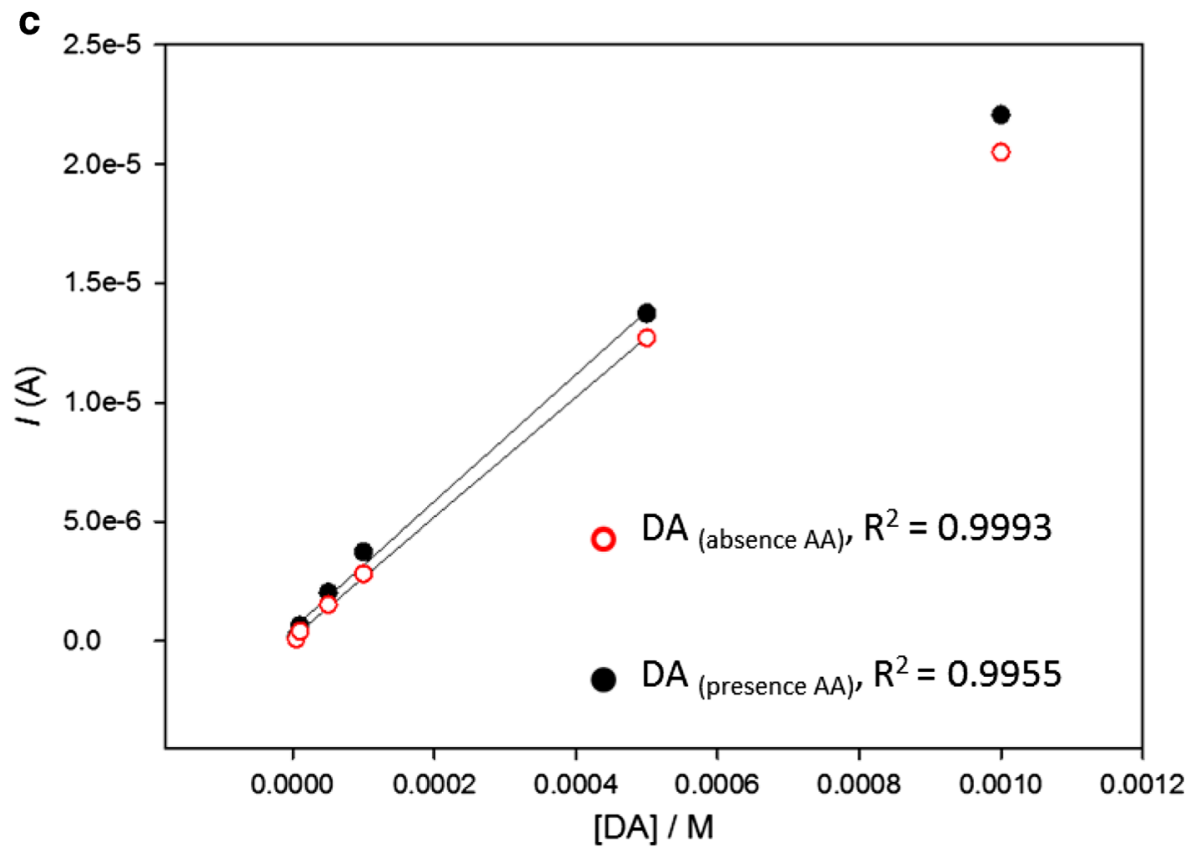

Fig. 8 a Cyclic voltammograms recorded at S- $\beta$-CDCPE in increasing concentrations of DA $\left(5 \times 10^{-6} \mathrm{M}, 5 \times 10^{-5} \mathrm{M}, 1 \times 10^{-4} \mathrm{M}, 5 \times 10^{-4} \mathrm{M}\right.$, and $\left.1 \times 10^{-3} \mathrm{M}\right)$ in the absence of AA and $\mathbf{b}$ in the presence of $1 \times 10^{-3} \mathrm{M}$ AA. Inset b enlarged voltammograms of DA $\left(5 \times 10^{-6} \mathrm{M}, 5 \times 10^{-5} \mathrm{M}\right.$,

concentrations of DA (from $5 \times 10^{-6} \mathrm{M}$ to $1 \times 10^{-3} \mathrm{M}$ ) in $0.1 \mathrm{~PB}(\mathrm{pH}$ 6.8). The current response reveals that DA oxidation peak current is directly proportional to concentration within the range $5 \times 10^{-6} \mathrm{M}-5 \times 10^{-4} \mathrm{M}$, returning the regression equation, $I_{\mathrm{pa}}(\mathrm{A})=0.0252[\mathrm{DA}](\mathrm{M})+1.5205 \times 10^{-7}$ $\left(R^{2}=0.9955\right)$, as illustrated in Fig. 8c. Moreover, the calibration plots of DA in the absence of AA shows that the relationship between anodic peak current and concentration of DA is also linear between $5 \times 10^{-6} \mathrm{M}$ and $5 \times 10^{-4} \mathrm{M}$, with the linear regression equation as $I_{\mathrm{pa}}(\mathrm{A})=0.036[\mathrm{DA}](\mathrm{M})+$ $1.461 \times 10^{-7}\left(R^{2}=0.9993\right)$. As observed in Fig. 8c, there is a slight deviation from linearity from $5 \times 10^{-4} \mathrm{M}$ to $1 \times 10^{-3} \mathrm{M}$ in both cases, probably due to electrode fouling effect at $1 \times 10^{-3} \mathrm{M}$ DA. The current response of DA in the $\left.1 \times 10^{-4} \mathrm{M}\right)$ in the presence of AA $\left(1 \times 10^{-3} \mathrm{M}\right)$; $\mathbf{c}$ calibration curve of DA in the absence and in the presence of AA. Supporting electrolyte $0.1 \mathrm{M} \mathrm{PB}$ (pH 6.8). Scan rate $50 \mathrm{mV} / \mathrm{s}$

solution mixture (AA/DA) remains almost the same as when it was studied independently, indicating that the presence of AA has a minimal effect on the electrochemical reaction of DA at the electrode surface. These experimental results demonstrate the effectiveness of S- $\beta$-CDCPE in the sensing of DA.

The lowest experimentally determined concentration of DA at S- $\beta$-CDCPE using cyclic voltammetry was found to be $5 \times 10^{-6} \mathrm{M}$. In an attempt to detect concentrations of DA, lower than $5 \times 10^{-6} \mathrm{M}$, DPV was employed. The resulting voltammetric response of S- $\beta$-CDCPE at various DA concentrations shows that DA oxidation peak currents increase with increasing concentration from $5 \times 10^{-7} \mathrm{M}$ to $1 \times 10^{-3} \mathrm{M}$ as illustrated in Fig. 9. The plot of anodic peak current against concentration of DA shows a linear dynamic range of 

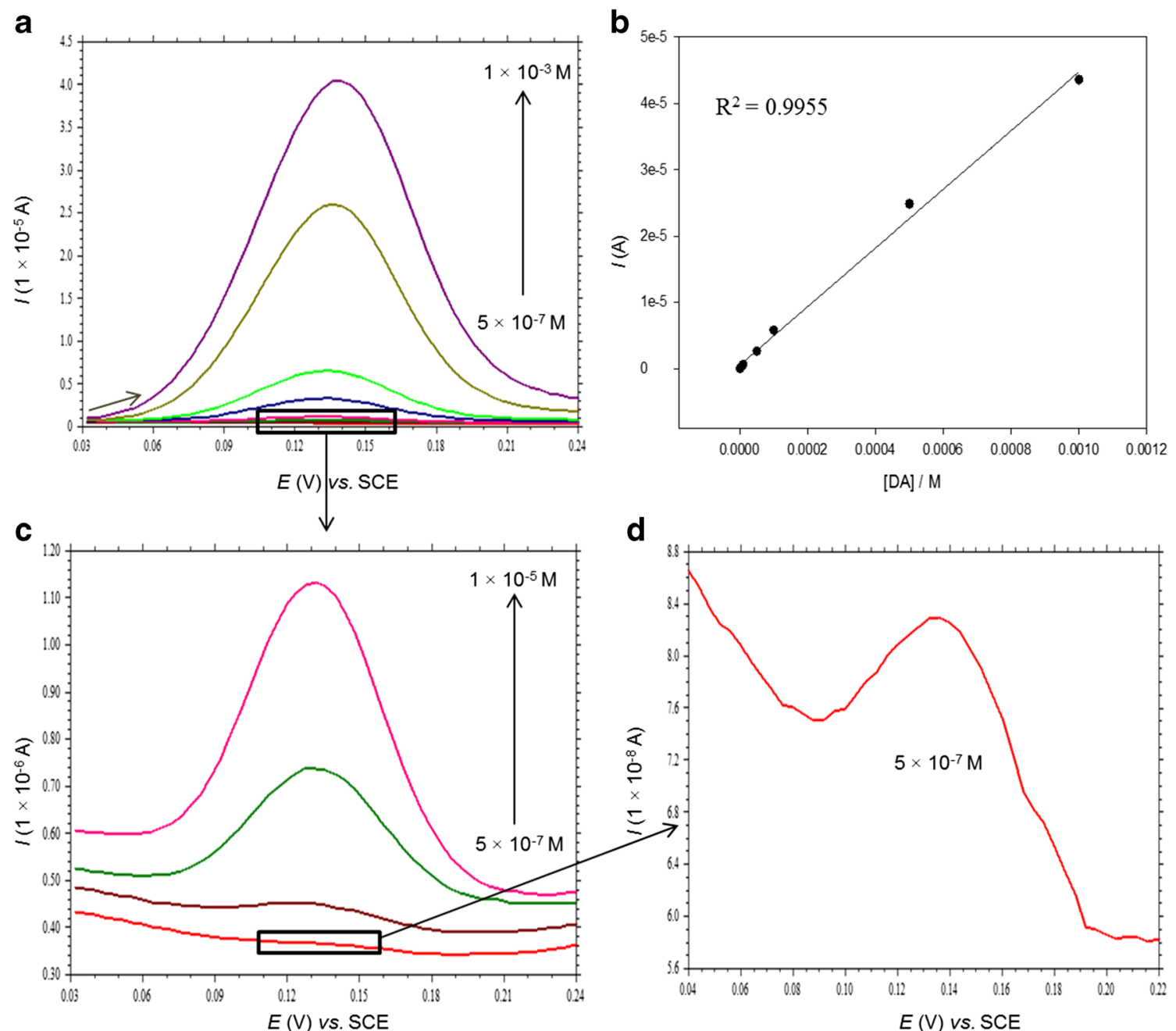

Fig. 9 a Differential pulse voltammograms of various concentrations of DA $\left(5 \times 10^{-7} \mathrm{M}, 1 \times 10^{-6} \mathrm{M}, 5 \times 10^{-6} \mathrm{M}, 1 \times 10^{-5} \mathrm{M}, 5 \times 10^{-5} \mathrm{M}\right.$, $1 \times 10^{-4} \mathrm{M}, 5 \times 10^{-4} \mathrm{M}$, and $\left.1 \times 10^{-3} \mathrm{M}\right)$ recorded at S- $\beta$-CDCPE; $\mathbf{b}$ the corresponding DA calibration curve. $\mathbf{c}$ Enlarged voltammograms for

$5 \times 10^{-7} \mathrm{M}-5 \times 10^{-4} \mathrm{M}$ with a correlation coefficient value of 0.9955 . The linear regression equation for this range is $I_{\mathrm{pa}}$ $(A)=0.044[D A](M)+5.008 \times 10^{-7}$. Therefore, the limit of detection (LOD) was calculated to be $1.33 \times 10^{-7} \mathrm{M}$, based on the $3 S_{\mathrm{b}} / m$ formula [37], where $S_{\mathrm{b}}$ is the standard deviation of the blank response (for $n=3$ ) and $m$ is the slope of the linear calibration plot. This novel sensor possesses high sensitivity with wide linear dynamic range for DA detection and can be compared with other cyclodextrin-modified carbon-based electrodes reported in the literature for the electrochemical detection of DA (Table 1).

\section{Determination of DA in the Presence of $A A$ and $5-H T$ at $S-\beta-C D C P E$}

The development of a selective method for the detection of DA in cerebrospinal fluid is highly desirable for analytical

$1 \times 10^{-5} \mathrm{M}, 5 \times 10^{-5} \mathrm{M}, 1 \times 10^{-4} \mathrm{M}, 5 \times 10^{-4} \mathrm{M}$, and $1 \times 10^{-3} \mathrm{M} \mathrm{DA}$; d background-subtracted voltammogram for $5 \times 10^{-7} \mathrm{M}$ DA. Supporting electrolyte $0.1 \mathrm{M} \mathrm{PB}$ (pH 6.8). Amplitude $0.05 \mathrm{~V}$, pulse width $0.05 \mathrm{~s}$, and pulse period $0.2 \mathrm{~s}$

applications and for diagnostic research [40, 41]. To mimic the extracellular space of the brain, aCSF was used instead of $\mathrm{PB}$ as supporting electrolyte solution. In addition, microelectrodes with diameter less than $250 \mu \mathrm{m}$ were utilized, which consist of unmodified CPE or $m \mathrm{~S}-\beta$-CDCPE (working electrodes), $\mathrm{Ag} / \mathrm{AgCl}$ wire (reference electrode), and $\mathrm{Ag}$ wire (counter electrode). These electrodes can be exploited for the in vivo electrochemical study of DA, as their robustness and microsize are suitable for implantation in brain tissue.

Figure 10 depicts the DPV voltammograms recorded at both the unmodified and modified microelectrodes using DA solution $\left(2 \times 10^{-4} \mathrm{M}\right)$ in the presence of AA $\left(1 \times 10^{-3} \mathrm{M}\right)$ and 5 -HT $\left(2 \times 10^{-4} \mathrm{M}\right)$, another electron active species that populates the cerebrospinal fluid. The voltammetric response of the unmodified CPE (Fig. 10, trace a) exhibits only two peaks, one broad peak at $c a$. $0.250 \mathrm{~V}$ (vs. $\mathrm{Ag} / \mathrm{AgCl}$ ), corresponding to the overlapping 
Table 1 The comparison of the performance of S- $\beta$-CDCPE with reported cyclodextrin modified carbon electrodes for the electrochemical determination of DA

\begin{tabular}{|c|c|c|c|c|}
\hline Working electrode & Linear dynamic range $(\mathrm{M})$ & LOD (M) & $\begin{array}{l}\text { Technique } \\
\text { used }\end{array}$ & References \\
\hline MWCNT/ $\beta-\mathrm{CD} / \mathrm{GCE}$ & {$\left[1.00 \times 10^{-5}-8.00 \times 10^{-5}\right]$} & $6.70 \times 10^{-6}$ & $\mathrm{CV}$ & {$[15]$} \\
\hline$\beta-\mathrm{CD} / \mathrm{MWCNTs} / \mathrm{Plu}-\mathrm{AuNPs} / \mathrm{GCE}$ & {$\left[1.00 \times 10^{-6}-5.60 \times 10^{-5}\right]$} & $1.90 \times 10^{-7}$ & DPV & {$[38]$} \\
\hline AuNPs- $\beta-C D-G r a$ & {$\left[5.00 \times 10^{-7}-1.50 \times 10^{-4}\right]$} & $1.50 \times 10^{-7}$ & SWV & [39] \\
\hline $\mathrm{GR} / \beta-\mathrm{CD} / \mathrm{GCE}$ & {$\left[1.00 \times 10^{-7}-5.85 \times 10^{-5}\right]$} & $1.10 \times 10^{-8}$ & DPV & [13] \\
\hline $\mathrm{PPy} / \mathrm{S}-\beta-\mathrm{CD} / \mathrm{GCE}$ & - & $3.20 \times 10^{-6}$ & $\mathrm{RDV}$ & [16] \\
\hline S- $\beta$-CDCPE & {$\left[5.00 \times 10^{-7}-5.00 \times 10^{-4}\right]$} & $1.33 \times 10^{-7}$ & DPV & This work \\
\hline
\end{tabular}

$L O D$ limit of detection, $\beta-C D$ beta-cyclodextrin, $G C E$ glassy carbon electrode, $M W C N T$ s multiwalled carbon nanotubes, $P l u$-AuNPs poly(luminol)-gold nanoparticles, Gra graphene, GR graphite, $P P y$ polypyrrole, $S$ - $\beta-C D$ sulfated $\beta-\mathrm{CD}, C P E$ carbon paste electrode signal of AA and DA. The second peak occurring at $0.426 \mathrm{~V}$ (vs. $\mathrm{Ag} / \mathrm{AgCl}$ ) represents the oxidation of 5-HT. Similar observations at bare electrodes were reported in the literature $[42,43]$, demonstrating that bare electrodes cannot be used for the simultaneous electrochemical detection of DA, AA, and 5-HT. On the other hand, the oxidation peak potentials of AA, DA, and 5-HT at the $m \mathrm{~S}-\beta$-CDCPE (Fig. 10, trace b) are completely resolved into three well-defined peaks, located at $0.113,0.274$, and $0.371 \mathrm{~V}$ (vs. $\mathrm{Ag} / \mathrm{AgCl}$ ), respectively. The peak separations AA/DA, DA/5-HT, and AA/5-HT were $0.161,0.101$, and $0.258 \mathrm{~V}$, respectively, allowing the simultaneous determination of the three analytes. The shift of DA peak potential to the right at $m \mathrm{~S}-\beta-\mathrm{CDCPE}$ with respect to the overlapping peak potential of AA and DA at the unmodified CPE may be associated with the size of the sensor and/or the nature of the technique employed. By increasing the accumulation time ( $c a .2 \mathrm{~min}$ ) in the DPV mode, both analytes may have their respective peak potentials shifted to the left with $m$ S- $\beta$-CDCPE versus unmodified CPE. It is worth noting that the oxidation potential of AA, DA, and 5-HT are effectively separated at the corresponding macroscale electrode (see supplementary material Fig. S11). The modified microelectrode was next utilized to obtain DA calibration curves in the presence of the interfering species AA and 5HT. Figure 11 illustrates a series of DPV voltammograms obtained at $m \mathrm{~S}-\beta$-CDCPE in aCSF containing increasing DA concentrations $\left(4 \times 10^{-5} \mathrm{M}-1.4 \times 10^{-4} \mathrm{M}\right)$ in the presence of AA $\left(1 \times 10^{-3} \mathrm{M}\right)$ and 5 -HT $\left(3 \times 10^{-5} \mathrm{M}\right)$. DA oxidation peak current increases with the increase of DA concentrations in the ternary mixture, with a linear regression equation $I_{\mathrm{pa}}$ $(\mathrm{A})=0.00022[\mathrm{DA}](\mathrm{M})-7.487 \times 10^{-9}\left(R^{2}=0.9922\right)$ and a linear dynamic range $4 \times 10^{-5} \mathrm{M}-1.4 \times 10^{-4} \mathrm{M}$.

As discussed previously, the separation of the peak potentials between AA and DA observed at the modified electrode is primarily based on the difference in the charge carried by these species. At physiological $\mathrm{pH}, \mathrm{AA}$ is mainly anionic whereas DA is cationic. Since 5-HT $\left(\mathrm{p} K_{\mathrm{a}}=9.8\right)$ is also cationic, it should be electrostatically attracted to the sulfate groups and may form an inclusion complex with S- $\beta-C D$. This would suggest a competitive adsorption between DA and 5-HT at the modified electrode surface, as reported elsewhere [44]. The indole moiety of 5-HT may provide a relatively greater affinity with $\mathrm{S}-\beta-\mathrm{CD}$ cavity compared to benzene moiety of DA.
Fig. 10 Typical differential pulse voltammograms obtained from a solution mixture of $2 \times 10^{-4} \mathrm{M}$ DA, $2 \times 10^{-4} \mathrm{M} 5$-HT, and $1 \times 10^{-3} \mathrm{M}$ AA at unmodified $\mathrm{CPE}$ (trace $a$ ) and at $m \mathrm{~S}-\beta$ CDCPE (trace b). Supporting electrolyte aCSF. Amplitude $0.05 \mathrm{~V}$, pulse width $0.05 \mathrm{~s}$, and pulse period $0.2 \mathrm{~s}$

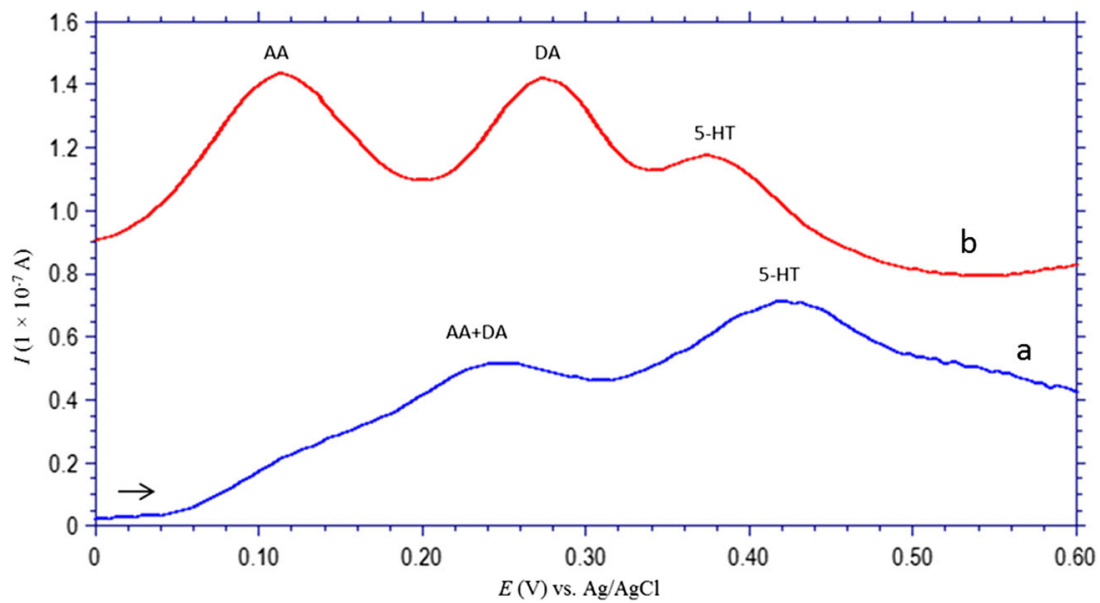


a

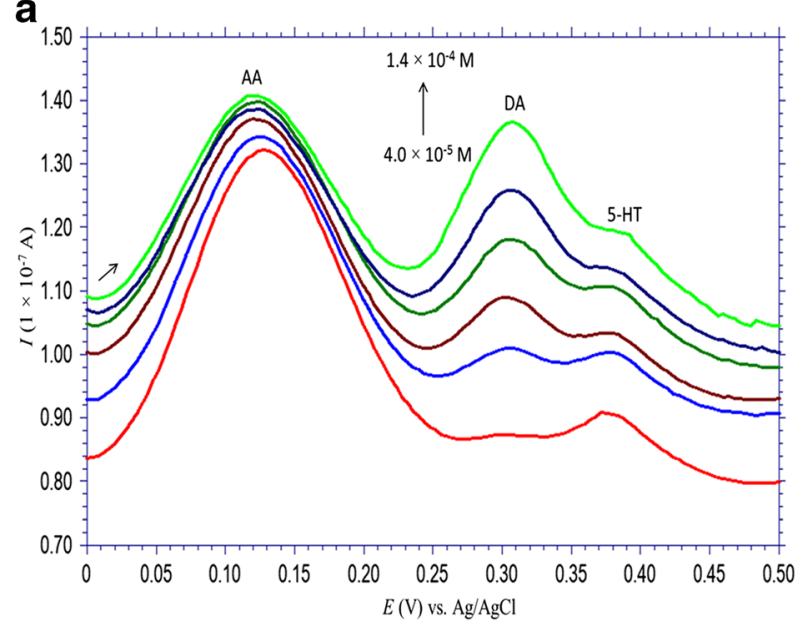

b

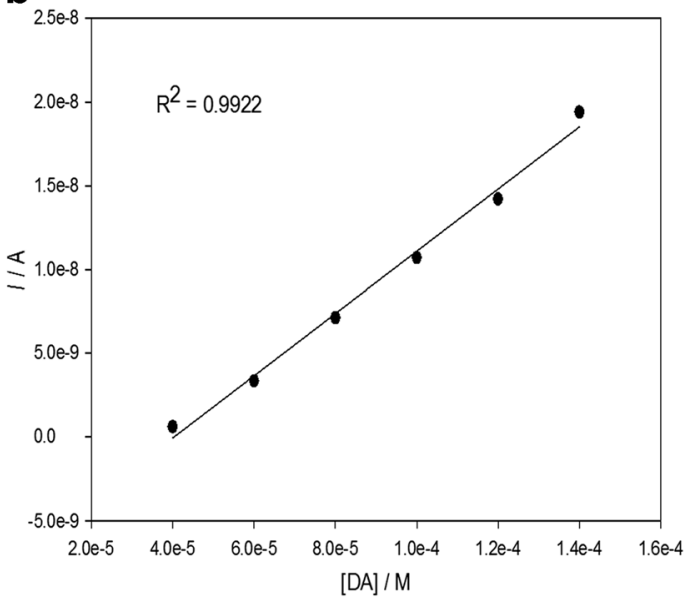

Fig. 11 a Typical differential pulse voltammograms recorded at $m \mathrm{~S}-\beta$ CDCPE in increasing concentrations of DA $\left(4.0 \times 10^{-5} \mathrm{M}, 6.0 \times 10^{-5} \mathrm{M}\right.$, $8.0 \times 10^{-5} \mathrm{M}, 1.0 \times 10^{-4} \mathrm{M}, 1.2 \times 10^{-4} \mathrm{M}$, and $\left.1.4 \times 10^{-4} \mathrm{M}\right)$ in the presence of AA $\left(1 \times 10^{-3} \mathrm{M}\right)$ and 5 -HT $\left(3 \times 10^{-5} \mathrm{M}\right)$; $\mathbf{b}$ the corresponding DA calibration curve. Supporting electrolyte aCSF. Amplitude $0.05 \mathrm{~V}$, pulse width $0.05 \mathrm{~s}$, and pulse period $0.2 \mathrm{~s}$

\section{Conclusions}

A novel and simple way for quantifying DA, using S- $\beta$ CDCPE, was presented in this study. The results have demonstrated that $\mathrm{S}-\beta$-CDCPE exhibit a 10 -fold increase in oxidation current response for DA when compared to the unmodified CPE. The limit of detection obtained was $1.33 \times 10^{-7} \mathrm{M}$, with the returned increase of the oxidation peak current intensity attributed to the pre-concentration of the DA at the electrode surface due to the interaction with S- $\beta$-CD. The optimal sensor design was made by impregnating $0.545 \mathrm{~g}$ S- $\beta-\mathrm{CD}$ in a carbon paste containing $0.71 \mathrm{~g}$ graphite and $200 \mu \mathrm{L}$ silicone oil. The mechanism of sensing has been determined to be a combination of host-guest and electrostatic interactions. The electrochemical behavior of the modified electrode is strongly dependent on solution $\mathrm{pH}$, with an almost Nernstian response. The mechanism diagnosis of DA oxidation at S- $\beta$-CDCPE reveals that the electron transfer was under adsorption-control. On the other hand, the miniaturized S- $\beta$-CDCPE has the ability to separate the anodic oxidation peak potentials of AA, DA, and 5-HT in aCSF with a well-defined peak separation and a strong current response. Our goal in the future work is to employ the developed sensor for the electrochemical detection of DA in rat brain.

\section{References}

1. P.I. Nagy, G. Alagona, C. Ghio, Theoretical studies on the conformation of protonated dopamine in the gas phase and in aqueous solution. J. Am. Chem. Soc. 121, 4804-4481 (1999)

2. R.M. Wightman, L.J. May, A.C. Michael, Detection of dopamine dynamics in the brain. Anal. Chem. 60, 769-779 (1988)
3. M.A. Piggott, E.F. Marshall, N. Thomas, S. Lloyd, J.A. Court, E. Jaros, D. Burn, M. Johnson, R.H. Perry, I.G. McKeith, C. Ballard, E.K. Perry, Striatal dopaminergic markers in dementia with Lewy bodies, Alzheimer's and Parkinson's diseases: rostrocaudal distribution. Brain 122, 1449-1468 (1999)

4. P. Seeman, H.B. Niznik, Dopamine-receptors and transporters in Parkinsons-disease and schizophrenia. FASEB J. 4, 2737-2744 (1990)

5. J.A. Stamford, P. Palij, C. Davidson, S.J. Trout, Fast cyclic voltammetry - neurotransmitter measurement in real-time and realspace. Bioelectrochem. Bioenerg. 38, 289-296 (1995)

6. C. Davidson, E.H. Ellinwood, S.B. Douglas, T.H. Lee, Effect of cocaine, nomifensine, GBR 12909 and WIN 35428 on carbon fiber microelectrode sensitivity for voltammetric recording of dopamine. J. Neurosci. Meth. 101, 75-83 (2000)

7. U. Yogeswaran, S.M. Chen, Separation and concentration effect of f-MWCNTs on electrocatalytic responses of ascorbic acid, dopamine and uric acid at f-MWCNTs incorporated with poly (neutral red) composite films. Electrochim. Acta 52, 5985-5996 (2007)

8. Z. Nasri, E. Shams, Application of silica gel as an effective modifier for the voltammetric determination of dopamine in the presence of ascorbic acid and uric acid. Electrochim. Acta 54, 7416-7421 (2009)

9. R.D. Oneill, Microvoltammetric techniques and sensors for monitoring neurochemical dynamics in-vivo - a review. Analyst 119, 767-779 (1994)

10. P. Hulthe, B. Hulthe, K. Johannessen, J. Engel, Decreased ascorbate sensitivity with Nafion-coated carbon-fiber electrodes in combination with copper(II) ions for the electrochemical determination of electroactive substances in vivo. Anal. Chim. Acta 198, 197-206 (1987)

11. K. Jackowska, P. Krysinski, New trends in the electrochemical sensing of dopamine. Anal. Bioanal. Chem. 405, 3753-3771 (2013)

12. K.T. Kawagoe, R.M. Wightman, Characterization of amperometry for in-vivo measurement of dopamine dynamics in the rat-brain. Talanta 41, 865-874 (1994)

13. S. Palanisamy, S. Sakthinathan, S.M. Chen, B. Thirumalraj, T.H. Wu, B.S. Lou, X.H. Liu, Preparation of $\beta$-cyclodextrin entrapped graphite composite for sensitive detection of dopamine. Carbohyd. Polym. 135, 267-273 (2016) 
14. M. Chen, X.J. Wei, H. Qian, G.W. Diao, Fabrication of GNPs/CDSH-Fc/nafion modified electrode for the detection of dopamine in the presence of ascorbic acid. Mat. Sci. Eng. C-Mater 31, 1271-1277 (2011)

15. G. Alarcon-Angeles, B. Perez-Lopez, M. Palomar-Pardave, M.T. Ramirez-Silva, S. Alegret, A. Merkoci, Enhanced host-guest electrochemical recognition of dopamine using cyclodextrin in the presence of carbon nanotubes. Carbon 46, 898-906 (2008)

16. C.C. Harley, A.D. Rooney, C.B. Breslin, The selective detection of dopamine at a polypyrrole film doped with sulfonated beta-cyclodextrins. Sensors Actuators B Chem. 150, 498-504 (2010)

17. J.J. Colleran, C.B. Breslin, Simultaneous electrochemical detection of the catecholamines and ascorbic acid at PEDOT/S- $\beta$-CD modified gold electrodes. J. Electroanal. Chem. 667, 30-37 (2012)

18. G.R. Zhang, X.L. Wang, X.W. Shi, T.L. Sun, $\beta$-Cyclodextrin-ferrocene inclusion complex modified carbon paste electrode for amperometric determination of ascorbic acid. Talanta 51, 1019-1025 (2000)

19. J.P. Lowry, M.G. Boutelle, M. Fillenz, Measurement of brain tissue oxygen at a carbon paste electrode can serve as an index of increases in regional cerebral blood flow. J. Neurosci. Meth 71, 177-182 (1997)

20. M.D. Hawley, S.V. Tatawawa, S. Piekarsk, R.N. Adams, Electrochemical studies of oxidation pathways of catecholamines. J. Am. Chem. Soc. 89, 447-450 (1967)

21. A.W. Sternson, R. Mccreery, B. Feinberg, R.N. Adams, Electrochemical studies of adrenergic neurotransmitters and related compounds. J. Electroanal. Chem. 46, 313-321 (1973)

22. U.E. Majewska, K. Chmurski, K. Biesiada, A.R. Olszyna, R. Bilewicz, Dopamine oxidation at per(6-deoxy-6-thio)-alpha-cyclodextrin monolayer modified gold electrodes. Electroanalysis 18, 1463-1470 (2006)

23. J. Armstrong, R.B. Barlow, Ionization of phenolic amines, including apomorphine, dopamine and catecholamines and an assessment of Zwitterion constants. Brit. J. Pharmacol 57, 501-516 (1976)

24. G.P. Lewis, The importance of ionization in the activity of sympathomimetic amines. Brit. J. Pharm. Chemoth 9, 488-493 (1954)

25. M. Aslanoglu, S. Abbasoglu, S. Karabulut, A. Kutluay, Electrochemical determination of dopamine in the presence of ascorbic acid using a poly(3-acetylthiophene) modified glassy carbon electrode. Acta Chim. Slov. 54, 834-839 (2007)

26. S. Corona-Avendano, G. Alarcon-Angeles, M.T. Ramirez-Silva, G. Rosquete-Pina, M. Romero-Romo, M. Palomar-Pardave, On the electrochemistry of dopamine in aqueous solution. Part I: the role of [SDS] on the voltammetric behavior of dopamine on a carbon paste electrode. J. Electroanal. Chem. 609, 17-26 (2007)

27. K. Gmucova, M. Weis, D. Barancok, J. Cirak, P. Tomcik, J. Pavlasek, Ion selectivity of a poly(3-pentylmethoxythiophene) LB-layer modified carbon-fiber microelectrode as a consequence of the second order filtering in voltcoulometry. J. Biochem. Bioph. Meth 70, 385-390 (2007)

28. E. Laviron, General expression of the linear potential sweep voltammogram in the case of diffusionless electrochemical systems. J. Electroanal. Chem. 101, 19-28 (1979)

29. B. Hemmateenejad, A. Safavi, F. Honarasa, Electrochemical study of weak inclusion complex interactions by simultaneous MCRALS analyses of potential step-chronoamperometric data matrices. Anal. Methods 4, 1776-1782 (2012)
30. Z.N. Gao, X.L. Wen, H.L. Li, Study of the inclusion complexes of catecholamines with beta-cyclodextrin by cyclic voltammetry. Pol. J. Chem. 76, 1001-1007 (2002)

31. M.A. Kamyabi, F. Aghajanloo, Electrocatalytic response of dopamine at a carbon paste electrode modified with ferrocene. Croat. Chem. Acta 82, 599-606 (2009)

32. G.M. Hendy, C.B. Breslin, An electrochemical study in aqueous solutions on the binding of dopamine to a sulfonated cyclodextrin host. Electrochim. Acta 59, 290-295 (2012)

33. R. Zhang, G.D. Jin, D. Chen, X.Y. Hu, Simultaneous electrochemical determination of dopamine, ascorbic acid and uric acid using poly(acid chrome blue K) modified glassy carbon electrode. Sensors Actuators B Chem. 138, 174-181 (2009)

34. X.H. Lin, Y.F. Zhang, W. Chen, P. Wu, Electrocatalytic oxidation and determination of dopamine in the presence of ascorbic acid and uric acid at a poly (p-nitrobenzenazo resorcinol) modified glassy carbon electrode. Sensors Actuators B Chem. 122, 309-314 (2007)

35. M.A. Dayton, A.G. Ewing, R.M. Wightman, Response of microvoltammetric electrodes to homogeneous catalytic and slow heterogeneous charge-transfer reactions. Anal. Chem. 52, 23922396 (1980)

36. A. Domenech, H. Garcia, M.T. Domenech-Carbo, M.S. Galletero, 2,4,6-Triphenylpyrylium ion encapsulated into zeolite $\mathrm{Y}$ as a selective electrode for the electrochemical determination of dopamine in the presence of ascorbic acid. Anal. Chem. 74, 562-569 (2002)

37. R.N. Hegde, B.E.K. Swamy, N.P. Shetti, S.T. Nandibewoor, Electro-oxidation and determination of gabapentin at gold electrode. J. Electroanal. Chem. 635, 51-57 (2009)

38. D. Jia, J.Y. Dai, H.Y. Yuan, L. Lei, D. Xiao, Selective detection of dopamine in the presence of uric acid using a gold nanoparticlespoly(luminol) hybrid film and multi-walled carbon nanotubes with incorporated beta-cyclodextrin modified glassy carbon electrode. Talanta 85, 2344-2351 (2011)

39. X.Q. Tian, C.M. Cheng, H.Y. Yuan, J. Du, D. Xiao, S.P. Xie, M.M.F. Choi, Simultaneous determination of L-ascorbic acid, dopamine and uric acid with gold nanoparticles-beta-cyclodextringraphene-modified electrode by square wave voltammetry. Talanta 93, 79-85 (2012)

40. F. Gonon, M. Buda, R. Cespuglio, M. Jouvet, J.F. Pujol, In vivo electrochemical detection of catechols in the neostriatum of anesthetized rats - dopamine or dopac. Nature 286, 902-904 (1980)

41. F. Crespi, C. Mobius, In-vivo selective monitoring of basal levels of cerebral dopamine using voltammetry with nafion modified (NaCro) carbon-fiber microelectrodes. J. Neurosci. Meth 42, 149-161 (1992)

42. J.A. Wei, J.B. He, S.Q. Cao, Y.W. Zhu, Y. Wang, G.P. Hang, Enhanced sensing of ascorbic acid, dopamine and serotonin at solid carbon paste electrode with a nonionic polymer film. Talanta $\mathbf{8 3}$, 190-196 (2010)

43. X.H. Jiang, X.Q. Lin, Overoxidized polypyrrole film directed DNA immobilization for construction of electrochemical microbiosensors and simultaneous determination of serotonin and dopamine. Anal. Chim. Acta 537, 145-151 (2005)

44. J. Li, X.Q. Lin, Simultaneous determination of dopamine and serotonin on gold nanocluster/overoxidized-polypyrrole composite modified glassy carbon electrode. Sensors Actuators B Chem. 124, 486-493 (2007) 